\title{
Application of Chaos Theory for Power Quality Improvement
}

\author{
Mr. Rahul S. Bhagat ${ }^{1}$, Mr. Mahesh Meena ${ }^{2}$ \\ Assistant professor, Department of Electrical Engineering, J.E.S.I.T.M.R, Nashik, Maharashtra ${ }^{1}$ \\ Associate Professor, Department of Electrical Engineering, I.E.T, Alwar, Rajasthan ${ }^{2}$
}

\begin{abstract}
In a power system, active filter are used to improve the electrical power quality by providing either the necessary voltage signals to cancel the voltage disturbances added to the $50 \mathrm{~Hz}$ sine wave (voltage or series active filter), or the necessary harmonic currents that nonlinear loads demand (current or shunt active filter). Due to the switching operation of the active filter, the corresponding equations, based on the equivalent electrical circuits, are nonlinear with time-varying associated parameters. This work searches the feasibility of a dynamic analysis for active filter, basically Shunt active filter (current active filter) based on Chaos Theory, since this theory yields information about bounded regions having a non-periodic performance. The operation ranges for the shunt active filter before chaos occurring were found under the action of $\mathrm{p}-\mathrm{q}$ theory based controllers, justifying the superiority of the latter. A novel methodology has been presented, based on chaos theory and Poincare diagrams, to determine the dynamic analysis of Shunt Active Filter (SAF). Which will give the well idea about the value of harmonic's amplitude produced a chaotic motion in SAF.
\end{abstract}

Keywords: Power quality, active filter, nonlinear system, harmonic compensation

\section{BACKGROUND \& PRELIMINARIES}

As it is known, energy is a basic concept in both science and engineering. One complex dynamic system could be taken as an energy transformer, so it is able to be divided into many subsystems, which is simpler. The nonlinear and active loads are used wider and wider, such as motor driver, arc furnace and UPS and so on. These instruments improve the capacity of the control of power energy, but, at the same time, they also produce power pollution. The harmonics and reactive power component of current and unbalance in three-phase system reduce the efficiency of the power system.

Traditionally, the passive filters, composed of resistors, inductors and capacitors, are used to eliminate the harmonics. With the development of power electronics, active power filters are introduced to reduce harmonics current and compensate the reactive component. Commonly, the shunt active power filters are considered as a controllable current source which is connected in parallel with the mains. The harmonics and reactive components of the load current is drawn by the shunt active filter SAF, so the supply current is sinusoidal with unity power factor, that is, the phases of both supply current and voltage are the same. The control object is to make the output current of SAF equal to the harmonics and reactive power component of the load current. Chaos theory is used to search two aspects: First, to determine if current active filter (or Shunt active filter) is candidate topology for chaotic behaviour.

The history of Chaos Theory and Poincare Map is discussed here; extensive use of power electronics devices in power system and due which the system is goes more dynamical. So, the interest in nonlinear oscillations was growing, driven largely by developments in electronics. This paper also noted the coexistence of periodic orbits of different period (sub-harmonics of two distinct orders), which implied the existence of a complicated unstable invariant set.

\section{POWER QUALITY}

The power quality issue is defined as lany occurrence manifested in voltage, current, or frequency deviations those results in damage, upset, failure, or disoperation of end-use equipment." Almost all power quality issues are closely related with power electronics in almost every aspect of commercial, domestic, and industrial application.

\section{HARMONICS}

Harmonics voltages and currents in an electric power system are a result of non-linear electric loads. Harmonic frequencies in the distribution power system are a frequent cause of power quality problems. Harmonics in power systems result in increased heating in the equipment and conductors, missing in variable speed drives, and torque pulsations in motors. Reduction of harmonics is considered desirable.

\section{DESCRIPTION OF CHAOS}

Although there is no a definite definition of chaos, its dynamical properties can be de-scribed as follows:

Chaos is a periodic, long-term behaviour, in a deterministic system that exhibits sensitive dependence on initial conditions. A periodic long-time behaviour means that trajectories in the phase portrait of a system do not settle down towards fixed points, periodic orbits, or quasiperiodic orbits. Deterministic means that the system has no random or noisy inputs or parameters. Sensitive dependence on initial conditions.

\section{BASIC OF THE P-Q THEORY}

The $p-q$ theory is primarily based on a set of instantaneous calculation of powers in time domain. Voltage and current are sampled instantaneously which means there is no 
restriction on the shape of their waveform, and it can be applied to three phase with or without a neutral wire. It is based in time domain rather than frequency domain. Thus, it is valid in the steady state and also in the transient state. This shows the theory is very flexible and efficient in designing controllers for active filters and power conditioners based on power electronics devices.

\section{USE OF P-Q THEORY IN SHUNT ACTIVE FILTER}

The original concept of active filtering was introduced by Strycula and Gyugyi in 1976. Now a shunt active filter can be implemented practically, and many shunt active filters are working all over the world. Their controllers determine in real time the compensating current reference, and source a power converter to synthesize the compensating current reference with high fidelity. Figure 1.Illustrates the basic idea behind the shunt current compensation. It shows a source supplying power to a nonlinear load that is being compensated by a shunt active filter. Shunt active filter is in actual is a shunt compensator. We assumed that the shunt active filter behaves as a three phase controlled current source that can generate harmonics in phase opposition depending upon current references Ica, Icb and Icc.

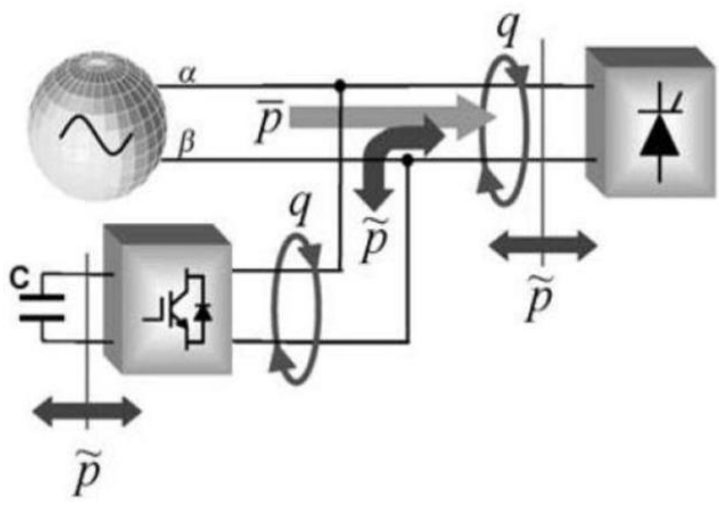

Figure 1: Optimal power flow

The calculated real power $\mathrm{p}$ of the load can be separated into its average $(p)$ and oscillating $(\sim p)$ parts. Likewise, the load imaginary power $\mathrm{q}$ can be separated into its average (q) and oscillating ( $\sim$ ) parts. Then, undesired portions of the real and imaginary powers of the load that should be compensated are selected.

\section{MODELLING AND DYNAMIC ANALYSIS OFSAF}

\section{SAF Introduction}

Static response of passive harmonic filter and other problems have led to a power electronic solution of harmonic distortion i.e. Active Harmonic Filter; a modern solution to old harmonic current problems. Nowadays, passive filters are used to cancel the switching frequency of active filters and high frequencies. Tuned filters are used besides the active filters to cancel specific frequencies and decrease the power of active filters. Active filters have been designed, improved, and commercialized in the past three decades. They are applicable to compensate current-based distortions such as current harmonics, reactive power, and neutral current.
They are also used for voltage-based distortions such as voltage harmonics, voltage flickers, voltage sags and swells, and voltage imbalances and load unbalancing and neutral shifting. Moreover, unlike passive filters, they do not cause harmful resonances with the power distribution systems. Consequently, the active harmonic filter's performances are independent of the power distribution system properties. The shunt-connected active power filter, with a self-controlled dc bus, has a topology similar to that of a static compensator (STATCOM) used for reactive power compensation in power transmission systems. Shunt active power filters compensate load current harmonics by injecting equal-but opposite harmonic compensating current. In this case the shunt active power filter operates as a current source injecting the harmonic components generated by the load but phase-shifted by 1800 .

\section{Operation of SAF}

The main aim of the Active Harmonic Filter (AHF) is to compensate for the harmonics and reactive power dynamically. The AHF overcomes the drawbacks of passive filters by using the switching mode power converter to perform the harmonic current elimination.

Compensation current signals are fed to hysteresis controller or Pulse Width Modulation (PWM) converter as reference signals to generate gating signals for fast switching Insulated Gate Bipolar Transistor (IGBT) inverter. The inverter generates harmonic currents required by the load through charging and discharging of capacitor. These cur-rents are injected into the system near the load through an interfacing inductor or a coupling transformer. The performance of AHF is independent of system impedance as it compares the injected currents with reference signals and tries to minimize the error. The Figure 2 shows operational waveform that generated by SAF; there are three topologies of AHF: i) Series AHF, ii) Shunt AHF and iii) Hybrid AHF. We have selected Shunt AHF (i.e. Shunt Active Filter or Current Active Filter) for this study which is ideal for current harmonic compensation. A generalize block diagram of SAF is given in Figure (2)

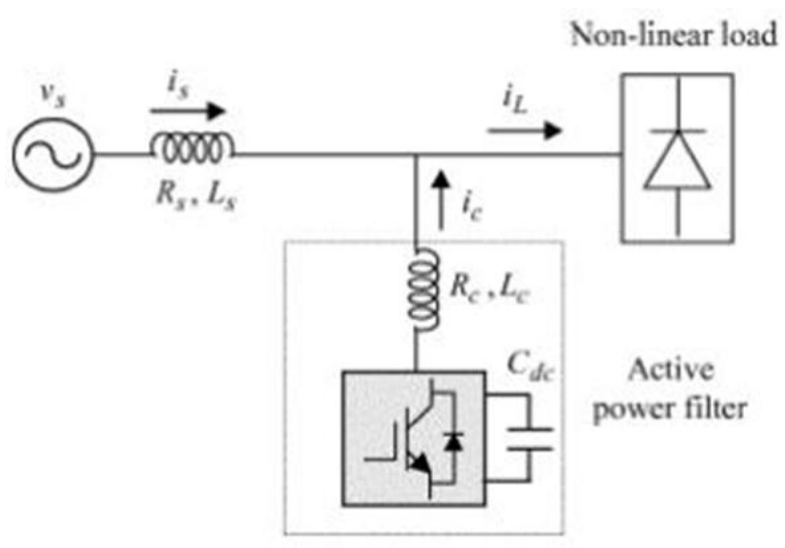

Figure 2: General block diagram of SAF

Shunt Active filter Controller based on p-q Theory: The Distribution system we considered for research contains 3-phase source, line inductance, nonlinear load and shunt active filter. As shown in Figure 3; 


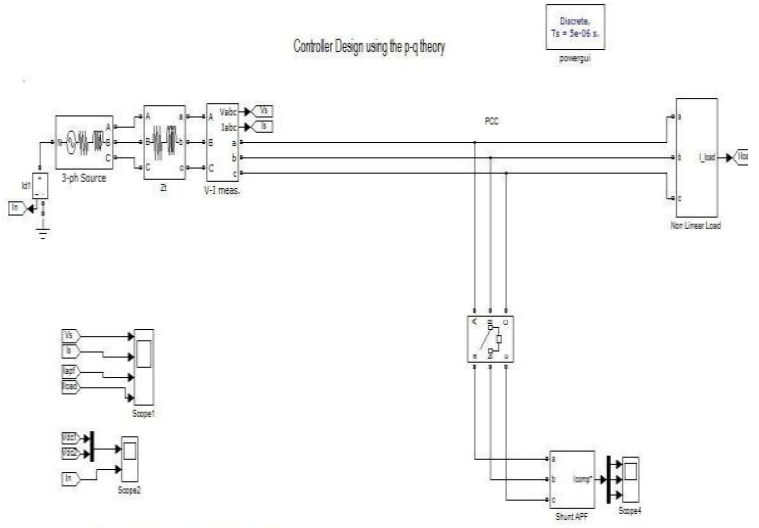

SHUNT ACTIVE POWER FLITER

Figure 3: Distribution system SIMULINK diagram

The SIMULINK diagram of active filter controller based on the pq-Theory is shown in Figure 3,

The PWM converter takes synthesizing action on compensating current. The filter control block has the job perform signal analysis in real time to calculate the instantaneous compensatory reference current signals. Figure 4 shows the most common topology of an active filter for harmonic compensation (maximum compensation) of a specific non-linear load. It consists of a voltage source inverter with a PWM current control, here hysteresis current control, and an active filter controller that performs an instantaneously working controlalgorithm. The shunt active filter controller works in a closed-loop manner, continuously acquiring the samples of the load current and calculating the instantaneous values of the compensating current reference ic for the PWM converter. In an ideal case, the PWM converter may be considered as a linear power amplifier, where the compensating current Ic tracks correctly its reference.

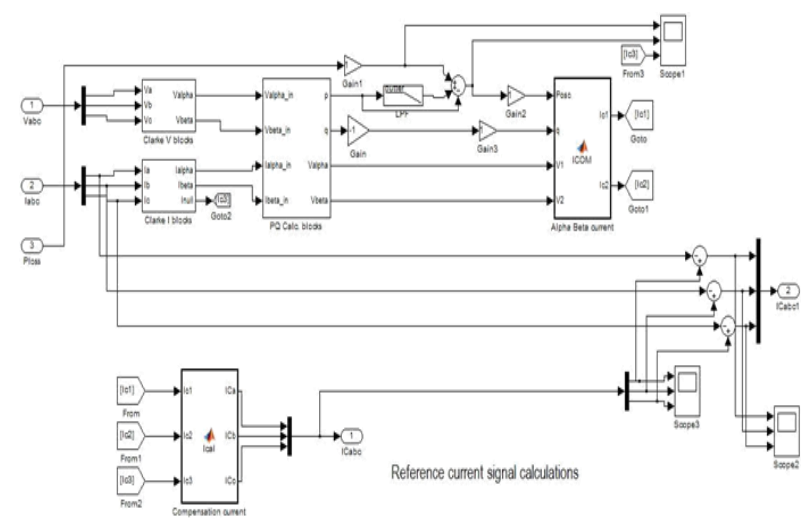

Figure 4: SIMULINK diagram for Compensation current calculation

\section{Simulation results of Shunt Active Filter:-}

For observing the dynamic behaviour SAF we can consider many types of load, like non-linear load, nonlinear plus balance resistive load, nonlinear plus unbalance resistive load, nonlinear load with $\mathrm{R} \mathrm{L} \mathrm{C} \mathrm{circuit}$ etc. Here we find the result for compensation of nonlinear plus unbalance resistive load. This case is simulated to show the dynamic.

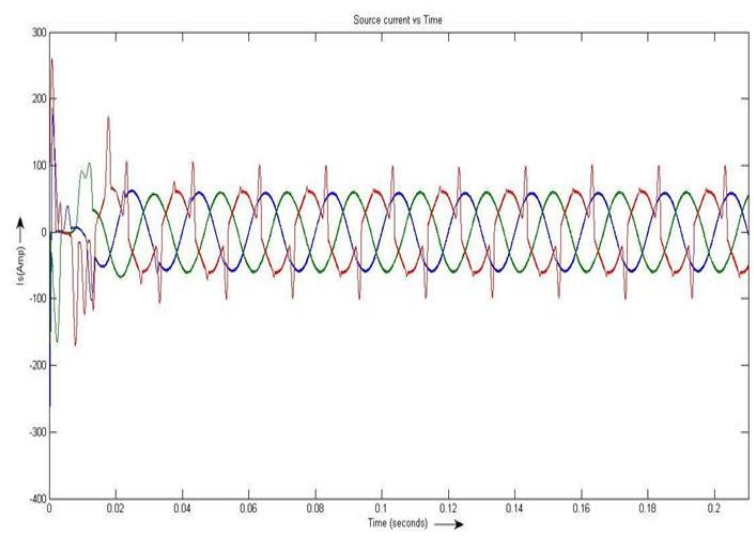

Figure 5: Sinusoidal waveform of source current

Behaviour of the SAF. The SAF is switched on at 0.4 seconds with the non-linear load only. These switching instants and the dynamic behaviour of the SAF can easily be observed

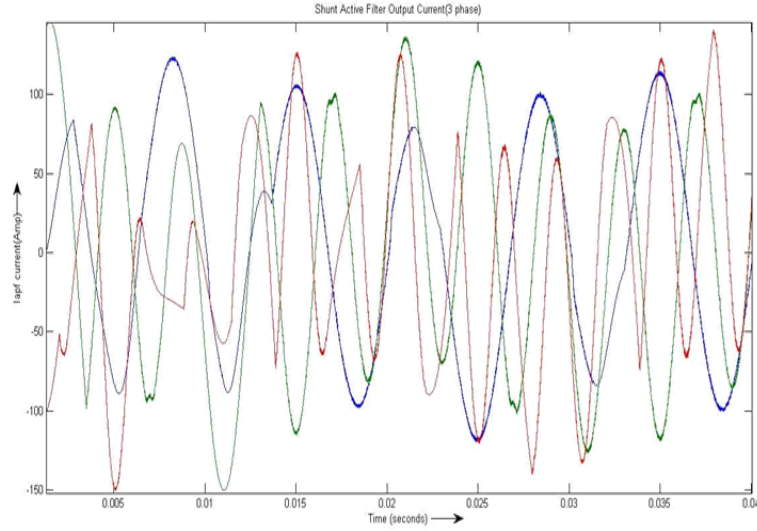

Figure 6: Injected load harmonic current waveform

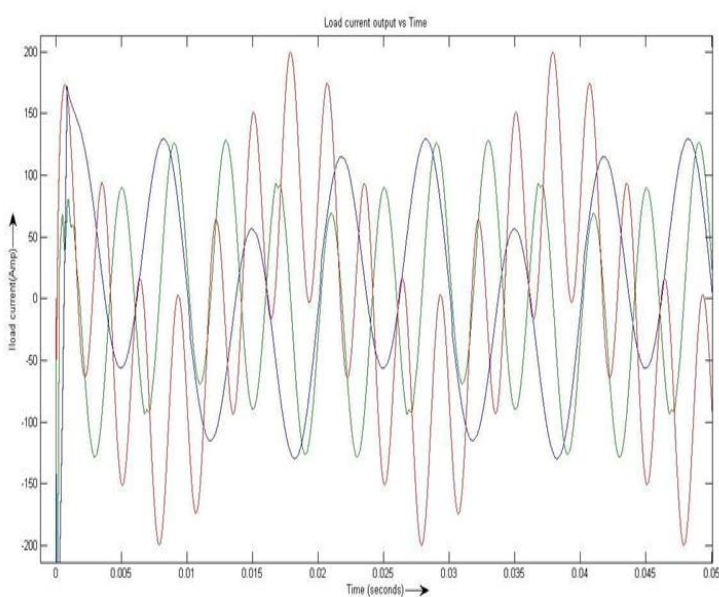

Figure 7: Injected load harmonic current waveform

\section{Dynamic Analysis of Shunt Active Filter}

The SAF system is nonlinear, deterministic, with dimension $n=3$. For existence of a chaotic behaviour it becomes necessary to check if it has an aperiodic behaviour and if it present a sensitive dependence on initial conditions.

The result presented in this section is obtained for particular case when the nonlinear load demands the 
Harmonic current;

$\mathrm{IL}=\mathrm{IP} \quad[\mathrm{a} \sin (!)+\mathrm{b} \sin (5 \quad$ !) + c $\sin (7 \quad$ !) + d $\sin (9$ !):::] (6.2.1)

The phase portrait of the PAF under a p-q theory based control action is depicted in Figure 8. It is not possible to know if there is a point, periodic or chaotic attractor in the phase portrait.

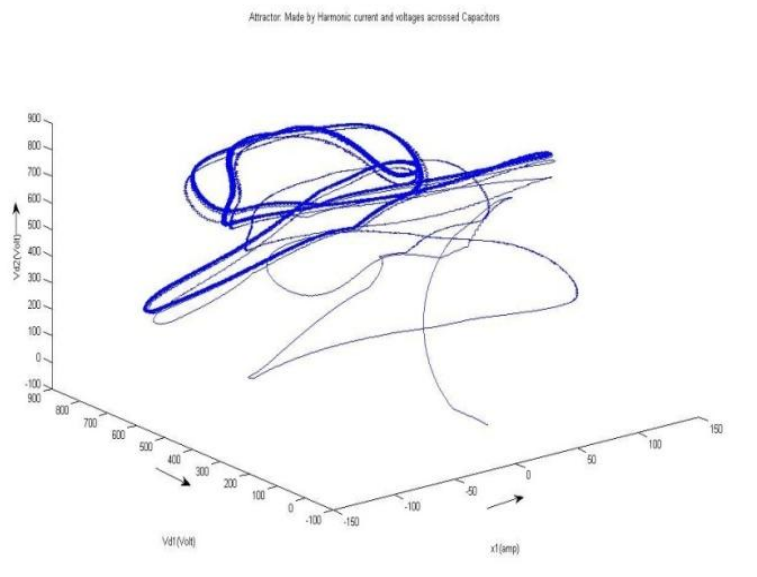

Figure 8: Phase Portrait of SAF

\section{CONCLUSION}

The $\mathrm{p}$ q Theory based controller has been analyses for power quality improvement. The shunt active filter is implemented for current harmonics of the nonlinear load. It is found from simulation results that $\mathrm{p} q$ theory along with shunt active filter improves power quality of the power system by eliminating harmonics of the nonlinear load.

In later stage analysis of shunt active filter is done. Shunt active filter do not present a chaotic behaviour as long as the corresponding design parameters do not change. However chaotic behaviour appears when the current harmonic amplitude is varied, particularly, when they become large enough. With the use of Poincare Maps to find out chaotic behaviour of shunt active filter under to different load conditions.

\section{FUTURE SCOPE}

Modelling and dynamic analysis of shunt active filter has been done in this thesis. It shows the chaotic behaviour of $\mathrm{SAF}$ ( $\mathrm{p} \mathrm{q}$ theory based controller is used). The work is to be extended to implementation of Passivity-Based Control via design of passive resistors using the concept of chaos and Poincare Map as discussed in the literature survey. Hence could be used to improve filter performance and power quality of power system. Future scope for this work is the presentation of a procedure for obtaining values for the passivity resistors by which the SAF behaves better.

\section{REFERENCES}

1] M. F. McGranaghan, R. C. Dugan, and H. W. Beaty(1012),IElectrical Power Sys-tems Quality", McGraw-Hill Professional, 2012.

[2] H. Akagi, E. H. Watanabe, and M. Aredes(2007), Instantaneous power theory and applications to power conditioning", vol. 31 . Wiley. com, 2007.
[3] D. C. Bhonsle and R. B. Kelkar(2011), IDesign and simulation of single phase shunt active power filter using MATLAB", Int. Conf. Recent Adv. Electr. Electron. Control Eng., pp. 237241, Dec. 2011.

[4] D. Wu, Y. Che, and K. W. E. Cheng(2009), IDesign and Performance of a Shunt Active Power Filter for Three- phase Fourwire System", Power Electronics Systems and Applications, 2009. 3rd International Conference, pp. 14, 2009.

[5] A. Chaoui, J.-P. Gaubert, F. Krim, and L. Rambault(2008), IOn the design of shunt active filter for improving power quality", IEEE Int. Symp. Ind. Electron., pp. 3137, Jun. 2008

[6] Deane H. B. Jonath and Hamill C. David(1990), Instability, Subharmonics, and Chaos in Power Electronic Systems ", IEEE Transactions on Power Electronics, pp. 260 268, July 1990.

[7] Hilborn C. Robert(2000), IChaos and Nonlinear Dynamics", Ed. Oxford, 2000

[8] Slotine Jean-Jac and Wiping Li(1991),\Applied Nonlinear Control", Ed. Prentice Hall, 1991.

[9] Oliver-Salazar Marco, Rodriguez Palacios Alejandro and Aguilar Justo Marv-ing(2003), IDynamic Analysis of Active Filter using Chaos Theory", Proceedings of the American Control Conference Denver, Colorado, pp. 4 6, 2003.

\section{BIOGRAPHIES}

Mr. Rahul Shankar Bhagat, B.E (Electrical), M. Tech (Power Systems), Assistant Professor Department of Electrical Engineering, JES, Institute of Technology and Management, Gangapur road, Nasik

Mr. Mahesh Meena, B.Tech (Electrical), M. Tech (Power Systems), Associate Professor, Department of Electrical Engineering, I.E.T, Alwar, Rajasthan. 